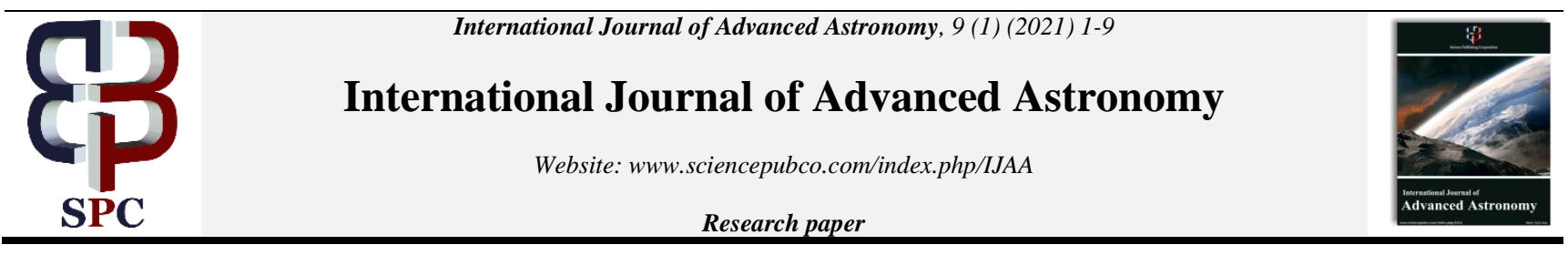

\title{
Occurrence characteristics of equatorial plasma bubbles over Kisumu, Kenya during Solar maximum of Solar Cycle 24
}

\author{
Uluma Edward $^{1 *}$, Ndinya Boniface ${ }^{1}$, Omondi George ${ }^{2}$ \\ ${ }^{1}$ Department of Physics, Masinde Muliro University of Science \& Technology, Kakamega, Kenya \\ ${ }^{2}$ Department of Physics and Materials Science, Maseno University, Maseno, Kenya \\ *Corresponding authorE-mail: nyogesa_edward@yahoo.com
}

\begin{abstract}
Equatorial Plasma Bubbles (EPBs) are irregular plasma density depletions in the ambient electron density in the equatorial F-region ionosphere generated after sunset. EPBs are known to bring disruptions to telecommunication and navigation systems. This paper investigates the occurrence of EPBs over Kisumu, Kenya (Geomagnetic coordinates: $9.64^{\circ} \mathrm{S}, 108.59^{\circ} \mathrm{E}$; Geographic coordinates: $0.02^{\circ} \mathrm{S}, 34.6^{\circ}$ E) for a few selected quiet and storm days between $1^{\text {st }}$ January 2013 and $31^{\text {st }}$ December 2014 which was a high Solar activity period for Solar Cycle 24. The study brings out EPB occurrence pattern over Kisumu, Kenya for the selected quiet and storm days of 2013 and 2014. The Receiver Independent Exchange (RINEX) data was retrieved from the Kisumu high data-rate NovAtel GSV4004B SCINDAGPS receiver. The data was unzipped and processed to obtain Vertical Total Electron Content (VTEC), amplitude scintillation ( $\left.\mathrm{S}_{4}\right)$ and Universal Time (UT) which were then fed into MATLAB to generate VTEC and $\mathrm{S}_{4}$ plots against UT for each selected quiet and storm day within the years 2013 and 2014. The Total Electron Content (TEC) depletion depths and $\mathrm{S}_{4}$ index values between 16:00 and 20:00 UT for each selected quiet and storm day were extracted from the VTEC and $\mathrm{S}_{4}$ plots and used to plot TEC depletion depths and $\mathrm{S}_{4}$ plots. The Rate of Change of TEC (ROT) and Rate of Change of TEC Index (ROTI) between 16:00 and 20:00 UT were generated from VTEC and used to plot ROT and the corresponding ROTI plots against UT. TEC depletion depths and ROTI values for each selected quiet and storm day between 16:00 and 20:00 UT were extracted and used to plot TEC depletion depths and ROTI plots and $\mathrm{S}_{4}$ index and ROTI plots. In this study, the enhancement of $S_{4}$ index corresponded well with TEC depletions, increased fluctuation of ROT and higher ROTI values between 16:00UT and 20:00UT for most days. This correspondence was used in inferring the occurrence of EPBs during the selected quiet and storm days of the years 2013 and 2014. The obtained results showed that the highest EPB occurrence was during March equinox with $33.33 \%$ occurrence in the year 2013 and $30.76 \%$ occurrence in the year 2014 , followed by the September equinox which had $20.38 \%$ occurrence in 2013 and $17.26 \%$ occurrence in 2014. The seasonal variation of EPB occurrence was attributed to the variation in the daytime $\mathbf{E} \times \mathbf{B}$ drift velocities. Larger $\mathbf{E} \times \mathbf{B}$ drift velocities resulted in increased EPB occurrence in the equinoctial period (March, April, August and September) and November solstice period (November and December) while lower $\mathbf{E}$ x $\mathbf{B}$ drift velocities resulted in reduced EPB occurrence in the June solstice period (June and July). The percentage EPB occurrence in the year 2013 was $6.49 \%$ while in the year 2014 was $4.32 \%$. The storm period had percentage EPB occurrence of $21.42 \%$ in the year 2013 and $21.88 \%$ in the year 2014 while the quiet period had percentage EPB occurrence of $18.75 \%$ in the year 2013 and $7.89 \%$ in the year 2014 . These results clearly showed that the percentage EPB occurrence was higher during the storm period than in the quiet period. Hence the development of EPBs was enhanced by geomagnetic activity through several competing dynamics such as Prompt Penetration Electric Field (PPEF), Disturbance Dynamo Electric Field (DDEF) and reduction in electron density due to increased recombination rates.
\end{abstract}

Keywords: Equatorial Plasma Bubbles; Total Electron Content; Rate of Change of TEC; Rate of Change of TEC Index; Solar Cycle 24.

\section{Introduction}

The Sun produces highly energetic particles such as X-rays and Ultraviolet (UV) radiations (Milos, 2014) which are harmful to the living things and the environment. Increased solar activity leads to large release of Coronal Mass Ejections (CME) and solar flares which causes a change in TEC when they reach the Earth. TEC is the total number of electrons in a column of $1 \mathrm{~m}^{2}$ cross-section between a GPS satellite and a GPS receiver (Murkherjee et al., 2010; Adewale et al., 2012; Radicella, 2012; Ndeda \& Odera, 2014; Magdaleno et al., 2017). Changes in TEC causes heightened levels of hazards in the Earth-space environment, storms and disruptions, generation of strong electric currents in the atmosphere and changes in the reflective properties of the ionosphere. During the day, the F-layer splits into two layers: F1 layer which is about $170 \mathrm{~km}$ and F2 layer which is about $250 \mathrm{~km}$ altitude. Conversely, at night the F1 layer diminishes and leaves the F2 layer which persists through the night. Thus, the sporadic E-layer and D-layer disappears a few hours before midnight (Milos, 2014) due to recombination between positive ions and electrons and migration of charged particles to higher altitudes. At the same time, the F-layer's lower regions rapidly recombine than its upper regions leading to a situation known as the Rayleigh-Taylor Instability (RTI) (Kelley, 2009). RTI is an unstable condition where a heavy fluid is held on top of a lighter fluid (Adewale et al, 2012) leading to bubbles of low density plasma being formed and pushed upwards towards the upper denser part of the F- region and growing to form 
bubbles which are 'frozen' into the moving ionosphere. These 'frozen' structures in the moving ionosphere are known as the plasma bubbles (Olwendo et al., 2012; Paznukhov et al., 2012).

Ionospheric irregularities and scintillations pose serious threats to technological systems that increasingly rely on trans-ionospheric radio propagation (Adewale et al., 2012) through signal degradation. In low latitude regions, these irregularities which are basically plasma bubbles are characterized by TEC depletions. During the day, dynamo electric fields which are generated by thermospheric winds in the equatorial E- region are propagated to the F-region altitudes along magnetic field lines. These dynamo electric fields are usually eastward during the day and brings an increase in the upward $\mathbf{E} \times \mathbf{B}$ plasma drift (Omondi et al., 2014; Caruana et al., 2018) that diffuses down the magnetic field lines and moves away from the equator due to action of gravity and pressure gradient force. This upward $\mathbf{E} \times \mathbf{B}$ plasma drift results in formation of ionization peaks in the sub-tropics on both sides of the equator called the Equatorial Ionization Anomaly (EIA) (Olwendo et al., 2012; Ndeda \& Odera, 2014). The EIA is an important feature in the study of ionospheric scintillations and is responsible for the formation of plasma density irregularities that give rise to stronger scintillations than at the magnetic equator (Das Gupta et al., 2004; Ndeda \& Odera, 2014). Various studies have been done on the chemical and physical processes taking place in the ionosphere leading to the occurrences of EPBs using the GPS due its accurate consistent performance worldwide and in these studies, TEC has been the key parameter (Adewale et al., 2012; Fayose et al., 2012; Wang et al., 2018) that has been very useful in the mitigation of ionospheric effects on radio systems (Makela et al., 2004; Paznukhov et al., 2012; Adewale et al., 2012; Magdaleno et al., 2017; Adetayo et al., 2017; Eastwood et al., 2017; Barros et al., 2018). Makela et al., (2004) studied seasonal variation of EPB occurrence from Haleakala, Hawaii between January 2002 and August 2003 (near solar maximum) period using both Airglow and GPS data and a probability for EPB development was $45 \%$ in April and $83 \%$ in September. In a study of L-band scintillations and TEC carried out by Adewale et al., (2012) in a GPS station in Lagos, Nigeria, the results showed the presence of some large scale depletions of TEC (or plasma bubbles) during evening hours and the TEC depletions corresponded well with increased fluctuation of ROT. Paznukhov et al., (2012) carried out a study on equatorial plasma bubbles and L-band scintillations in Africa during solar minimum and their results showed increase in EPB rate during June solstice moving west to East. They observed that seasonal occurrence of EPBs tended to shift towards boreal summer with fewer occurrences in equinox seasons. Magdaleno et al., (2017) also used GPS data to study climatology characterization of EPBs between 1998-2008 using 67 international GNSS stations around geomagnetic Equator and the obtained results on spatial analysis of EPBs showed that the largest rate of EPBs occurred at the Equator and South American sector but decreased as the distance of magnetic equator increased. Barros et al., (2018) carried out a study on the characteristics of EPBs using ground based network of more than 220 GNSS ground based receivers by mapping TEC (TEC maps) over South-America between November 2012 and January 2016 for both quiet and disturbed days. Their results showed that EPBs occurred majorly between September to March. Bolaji et al., (2019) also investigated the dynamics of ionospheric irregularities at different sectors in the month of March 2015 which consisted of both quiet and disturbed ionospheric conditions. The obtained results showed that the presence of severe irregularities were prominent in African and American sectors but rarer in Asian sectors. The strength was however found to decrease eastward and was attributed to the eastward decrease in the equatorial electrojet. In the equatorial region, the characteristics of plasma bubbles usually depend on the detection technique. In Ionosonde, plasma bubbles would manifest as Spread-F; in Airglow, they would manifest as plumes, while in GPS, they would manifest as TEC depletions. Although studies on the characterization and occurrence of plasma bubbles have been carried out in various parts of the equatorial region, more work needs to be done on the occurrence of EPBs over Africa even with the few available SCINDA-GPS receivers. The quiet time and storm time effects in the equatorial Africa needs more investigation due to the highly dynamic nature of the equatorial ionosphere (Omondi et al., 2019). In this paper we infer the occurrence of EPBs over Kisumu, Kenya using SCINDA-GPS TEC data for a few selected quiet and storm days between $1^{\text {st }}$ January 2013 and $31^{\text {st }}$ December 2014 . The occurrence of EPBs was inferred using TEC depletion depths, $\mathrm{S}_{4}$ index, ROT fluctuation and ROTI. The results presented in this paper on the occurrence of EPBs are needed so as to relate the extent of ionospheric irregularities to the possible disruptions of High Frequency communication signals as implied by $\mathrm{S}_{4}$. This has important implications for navigation and communication sectors.

\section{Materials and methods}

The Zipped RINEX data archived in the SCINDA-GPS receiver between $1^{\text {st }}$ January 2013 and $31^{\text {st }}$ December 2014 was retrieved and unzipped using the WinRAR program. The unzipped scintillation (.scn) files and position of the receiver (.psn) files were created in one folder and dragged into an open Gopi Software (Developed by Boston college and Dr. Gopi Seemala) which processed the raw GPS data to obtain a text (.Cmn) output file which was a more simplified ten column daily file of ionospheric observables separated by a tab: Jdatet, Time, PRN, Az, Ele, Lat, Lon, Stec, Vtec, and $\mathrm{S}_{4}$.

To reduce multipath effects resulting from obstruction from trees, tall buildings and other antennas, only data having elevation angles of $40^{\circ}$ and above was considered for use in this study. The filtered average daily data of VTEC, $\mathrm{S}_{4}$ and UT for all PRNs was obtained using SQL Server2017 program. The SQL Server2017 program produced the average daily VTEC and $\mathrm{S}_{4}$ values by averaging the VTEC and $\mathrm{S}_{4}$ values for all identical pseudo-random numbers (PRNs) within a 24-hour period.

The selected quiet and storm days of 2013 and 2014 period of study were obtained from the disturbance storm time (Dst) index using data obtained from the link: www.wdc.kug.kyoto-ua.ac.jp/dstdir. The quiet days considered in this study were days having Dst values $>$ $25 \mathrm{nT}$ while storm days considered in this study were days having Dst values $\leq-50 \mathrm{nT}$. The level of geomagnetic activity for the selected quiet and storm days was selected using the Planetary $\mathrm{K}(\mathrm{Kp})$ index obtained from the link: www.kugi.kyoto-ua.ac.jp/Kp, where the selected quiet days had $\mathrm{Kp}$ values ranging between 0 and 2 while the selected storm days had Kp values ranging between 3 and 9 .

The VTEC and $\mathrm{S}_{4}$ plots for each selected quiet and storm days of 2013 and 2014 were plotted against UT using MATLAB. TEC depletion depths and the corresponding $\mathrm{S}_{4}$ index for each selected quiet and storm day between 16:00 and 20:00UT were extracted and TEC depletion depths and $S_{4}$ plots were plotted as indicated in Figures 1(a), 1(b), 1(c) and 1(d). TEC depletion depth was obtained by finding the difference between the TEC value at the time of TEC depletion and the TEC value at the time of a TEC enhancement. The correspondence between TEC depletion depths and $\mathrm{S}_{4}$ for the selected quiet and storm days of the years 2013 and 2014 were noted and discussed.

ROT was calculated directly from the filtered average daily VTEC data within intervals of 120 seconds using equation (1) (Pi et al., 1997),

$$
R O T=\frac{T E C_{t}-T E C_{t-1}}{\Delta t}
$$


where, $\quad$ TEC $=$ Total Electron content

$\mathrm{t}$ and $\mathrm{t}-1=$ time difference between the epochs in minutes

$\Delta \mathrm{t}=$ time range in minutes

ROTI was computed from ROT at intervals of 4 minutes using equation 2. ROTI is the key component used to investigate ionospheric fluctuations (Bhattacharyya et al., 2000) and it provides spatial variation of electron density (Pi et al., 1997; Jacobsen, 2014).

$$
R O T I=\sqrt{\left\langle R O T^{2}\right\rangle-\langle R O T\rangle^{2}}
$$

ROT for each selected quiet and storm day and the corresponding ROTI were plotted against UT using MATLAB. The ROTI values for each selected quiet and storm day between 16:00 and 20:00 UT were extracted alongside their corresponding TEC depletion depths values. The extracted values were used to plot the TEC depletion depths and ROTI plots for the selected quiet and storm days of the years 2013 and 2014 as indicated in Fig. 2(a), 2(b), 2(c) and 2(d). The correspondence between TEC depletion depths and ROTI for the selected quiet and storm days of the years 2013 and 2014 were noted and discussed. The $\mathrm{S}_{4}$ values and their corresponding ROTI values for each selected quiet and storm days of 2013 and 2014 between 16:00 and 20:00 UT were also extracted and the obtained values used to plot the $\mathrm{S}_{4}$ and ROTI plots for the selected quiet and storm days of 2013 and 2014 as indicated Fig. 3(a), 3(b), 3(c) and 3(d). Their correspondence were also noted and discussed.

In this study, the presence of EPBs were inferred by checking for TEC depletions and their correspondence with enhanced $\mathrm{S}_{4}$, fluctuation of ROT and ROTI values after sunset. Since not all TEC depletions leads to formation of EPBs, the threshold for TEC depletions were set at TEC depletion depths $\geq 7$ TECU. The TEC depletion depths were to correspond with enhanced $\mathrm{S}_{4}$ index and increased fluctuations of ROT and high ROTI values $\geq 1.5 \mathrm{TECU} / \mathrm{min}$ after local sunset for each selected quiet and storm day. The TEC depletion depths and $\mathrm{S}_{4}$ index plots; TEC depletion depths and ROTI plots and $\mathrm{S}_{4}$ index and ROTI plots in Fig. 1(a), 1(b), 1(c), 1(d), 2(a), 2(b), 2(c), 2(d), 3(a), 3(b), 3(c) and 3(d) were analyzed with an aim of obtaining the days which met the set threshold for EPB occurrence.

\section{Results and discussions}

\subsection{Variations of TEC depletion depths and amplitude scintillations $\left(\mathrm{S}_{4}\right)$ for selected quiet and storm days of 2013 and 2014}

Fig. 1 shows TEC depletion depths and $\mathrm{S}_{4}$ plots for the selected quiet and storm days of 2013 and 2014 between 16:00 and 20:00 UT. In Fig. 1(a), a TEC depletion depth of 15 TECU was noted with a corresponding enhanced $\mathrm{S}_{4}$ index of 0.35 on $18^{\text {th }}$ April $2013.19^{\text {th }}$ April 2013 had a TEC depletion depth of 25 TECU with a corresponding enhanced $\mathrm{S}_{4}$ index of $0.5 .26^{\text {th }}$ September 2013 had a TEC depletion depth of 16 TECU with a corresponding enhanced $S_{4}$ index of 0.3 while $21^{\text {st }}$ November 2013 had a TEC depletion depth of 11 TECU with a corresponding enhanced $S_{4}$ index of 0.2 . The largest TEC depletion depths of 25 TECU on $19^{\text {th }}$ April 2013 and 16 TECU on $26^{\text {th }}$ September 2013 were attributed to increased solar activity since the days were within the equinoctial period. Increased solar activity leads to photoionization of neutral molecules through Solar Extreme Ultra-Violet (SEUV) radiation in the ionosphere. The smallest TEC depletion depths were on $26^{\text {th }}$ June $2013,4^{\text {th }}$ July 2013 and $24^{\text {th }}$ July 2013 and were attributed to low solar activity since the days were within the June solstice period. The TEC depletion depths were seen to correspond with enhanced $\mathrm{S}_{4}$ values of more than 0.2 after local sunset for most selected quiet days of 2013 as indicated by Fig. 1(a).

In Fig. 1(b), TEC depletions depths of 20 TECU were noted with a corresponding enhanced $\mathrm{S}_{4}$ index of 0.5 and 0.3 on $16^{\text {th }}$ April 2014 and $26^{\text {th }}$ August 2014 respectively. $3^{\text {rd }}$ February 2014 had a TEC depletion depth of 15 TECU with a corresponding enhanced $\mathrm{S}_{4}$ index of $0.3 .7^{\text {th }}$ October 2014 had a TEC depletion depth of 16 TECU with a corresponding enhanced $\mathrm{S}_{4}$ index of 0.25 while $13^{\text {th }}$ October 2014 had a TEC depletion depth of 3 TECU with a corresponding enhanced $\mathrm{S}_{4}$ index of 0.2. The TEC depletion depths of 20 TECU were observed on $16^{\text {th }}$ April 2014 and $26^{\text {th }}$ August 2014 were also attributed to increased solar activity during the said days. The TEC depletion depths were seen to correspond with enhanced $\mathrm{S}_{4}$ values of more than 0.1 after local sunset for most selected quiet days of 2014 as indicated in Fig. 1(b).

In Fig. 1(c), TEC depletion depths of 15 TECU were noted with a corresponding enhanced $S_{4}$ index of 0.5 and 0.3 on $24^{\text {th }}$ April 2013 and $5^{\text {th }}$ August 2013 respectively. $11^{\text {th }}$ November 2014 had a TEC depletion depth of 16 TECU with a corresponding enhanced $\mathrm{S}_{4}$ index of $0.2 .1^{\text {st }}$ March 2013 had a TEC depletion depth of 5 TECU with a corresponding enhanced $\mathrm{S}_{4}$ index of 0.1 while $8^{\text {th }}$ December 2013 had a TEC depletion depth of 10 TECU with a corresponding enhanced $S_{4}$ index of 0.1 . The largest TEC depletion depth of 16 TECU was on $11^{\text {th }}$ November 2014 and was attributed to the effect of an active storm (Dst index: -70nT) on that day. The TEC depletion depths of 15 TECU on $24^{\text {th }}$ April 2013 and $5^{\text {th }}$ August 2013 were attributed to the effect of increased solar activity (equinoctial period). The TEC depletion depths corresponded with enhanced $\mathrm{S}_{4}$ values of more than 0.1 for most selected storm days of 2013 after local sunset as indicated in Fig. 1(c).

In Fig. 1(d), TEC depletions depths of 18 TECU were noted with a corresponding enhanced $\mathrm{S}_{4}$ index of about 0.3 and 0.2 on $4^{\text {th }}$ March 2014 and $4^{\text {th }}$ May 2014 respectively. $12^{\text {th }}$ April 2014 had a TEC depletion depth of 15 TECU with a corresponding enhanced $\mathrm{S}_{4}$ index of 0.7. The $\mathrm{S}_{4}$ value of 0.7 on this day was the highest recorded $\mathrm{S}_{4}$ value for the whole study period. $12^{\text {th }}$ April 2014 was a storm day having a Dst index value of $-100 \mathrm{nT}$ and a Solar flux F10.7 cm of about $150 \mathrm{sfu}$ and hence this highest $\mathrm{S}_{4}$ value $(0.7)$ might be due to the effect of high Solar intensity and the effect of the storm on that day. $12^{\text {th }}$ September 2014 had a TEC depletion depth of 8 TECU with a corresponding enhanced $\mathrm{S}_{4}$ index of 0.3 while $7^{\text {th }}$ June 2014 had a TEC depletion depth of 3 TECU with a corresponding enhanced $\mathrm{S}_{4}$ index of 0.2. Largest TEC depletion depths (18 TECU) observed on $1^{\text {st }}$ March 2014 and $4^{\text {th }}$ May 2014 were attributed to the increased solar activity during the period. The TEC depletion depths for the selected storm days of 2014 corresponded well with enhanced $\mathrm{S}_{4}$ values of more than 0.2 for most selected storm days of 2014 after local sunset as indicated in Fig. 1(d).

Generally, the TEC depletion depths corresponded well with enhanced $\mathrm{S}_{4}$ values after local sunset for most selected quiet and storm days of the years 2013 and 2014 as indicated in Fig. 1(a), 1(b), 1(c) and 1(d). Higher amplitude scintillation values were seen for the selected days of March and April for both years. This is because, the eastward electric field during March and April was greater than for the other months. These variations of the eastward electric field was attributed to the zonal electric field in the equatorial ionosphere. It was also noted that the selected quiet days of the years 2013 and 2014 had larger TEC depletion depths than the selected storm days of the years 2013 and 2014. This might be due to the variation in the ionospheric behaviour during quiet period and storm period. During storm 
period, the ionospheric behaviour is controlled by several competing dynamics including the effect of PPEF, DDEF and a reduction in the electron density due to increased recombination rates.
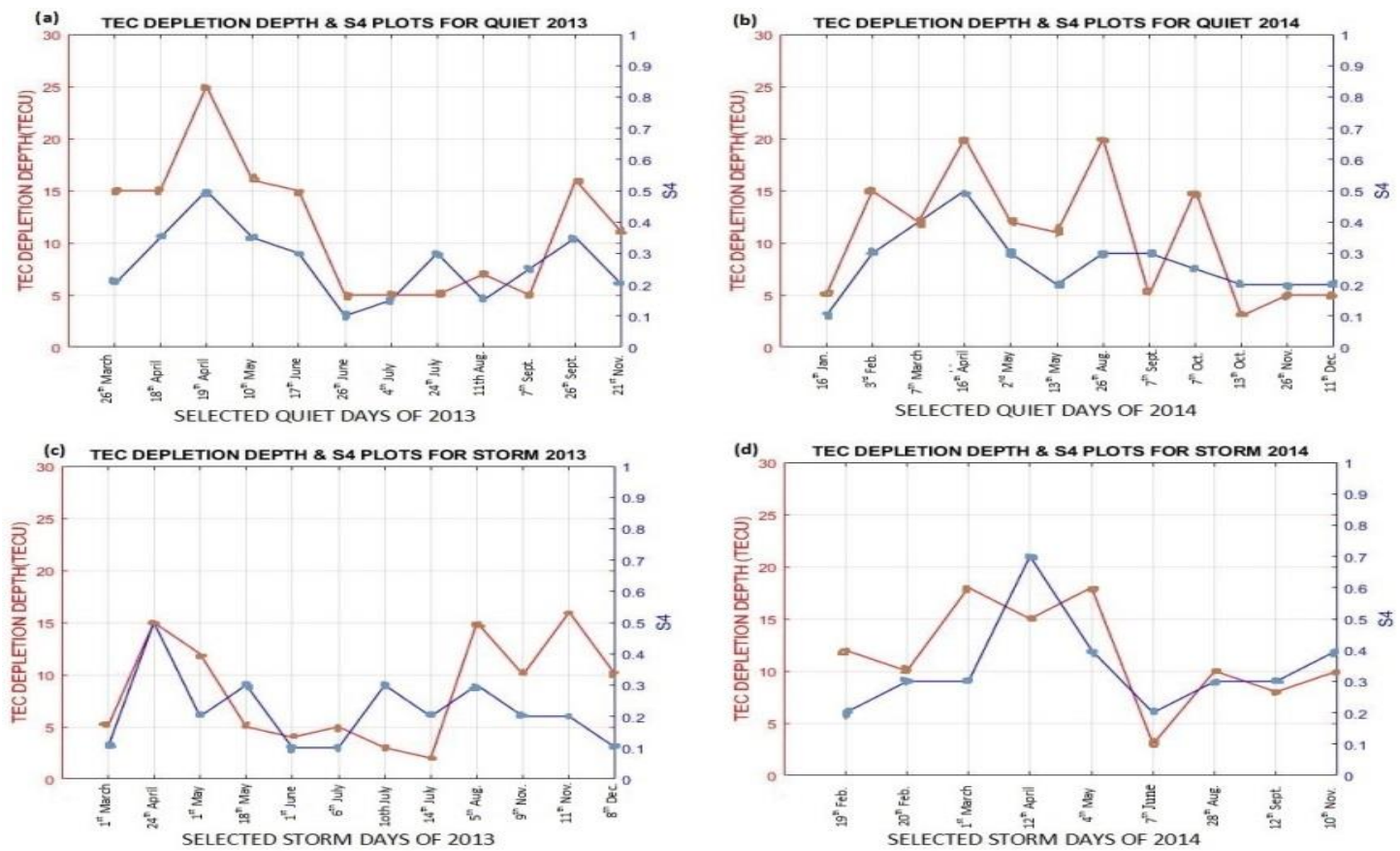

Fig. 1: TEC Depletion Depths and Amplitude Scintillation $\left(S_{4}\right)$ Plots for Selected Quiet and Storm Days of 2013 and 2014

\subsection{Variations of TEC depletion depths and ROTI for selected quiet and storm days of 2013 and 2014}

Fig. 2 shows TEC depletion depths and ROTI plots for the selected quiet and storm days of the years 2013 and 2014 between 16:00 and 20:00 UT.

In Fig. 2(a), TEC depletion depth of 25 TECU was noted with a corresponding ROTI of 1.9 TECU/min on $19^{\text {th }}$ April 2013. $10^{\text {th }}$ May 2013 had a TEC depletion depth of 16 TECU with a corresponding ROTI of 1.8 TECU/min. 26 ${ }^{\text {th }}$ March 2013 had a TEC depletion depth of 15 TECU with a corresponding enhanced $\mathrm{S}_{4}$ index of $1.9 \mathrm{TECU} / \mathrm{min}$ while $26^{\text {th }}$ June $2013,4^{\text {th }}$ July 2013 and $24^{\text {th }}$ June 2013 had TEC depletion depths of 5 TECU with a corresponding ROTI of 0 TECU/min.

In Fig. 2(b), TEC depletion depths of 20 TECU were noted with a corresponding ROTI of about 1.8 TECU/min on $16^{\text {th }}$ April 2014 and $26^{\text {th }}$ August 2014. $3^{\text {rd }}$ February 2014 and $7^{\text {th }}$ October 2014 had TEC depletion depths of 15 TECU with a corresponding ROTI of 1.8 TECU/min. $16^{\text {th }}$ January $2014,13^{\text {th }}$ October $2014,26^{\text {th }}$ November 2014 and $11^{\text {th }}$ December 2014 had TEC depletion depths of 5 TECU, 3 TECU, 5 TECU and 5 TECU respectively with a corresponding ROTI of 1.9 TECU/min.
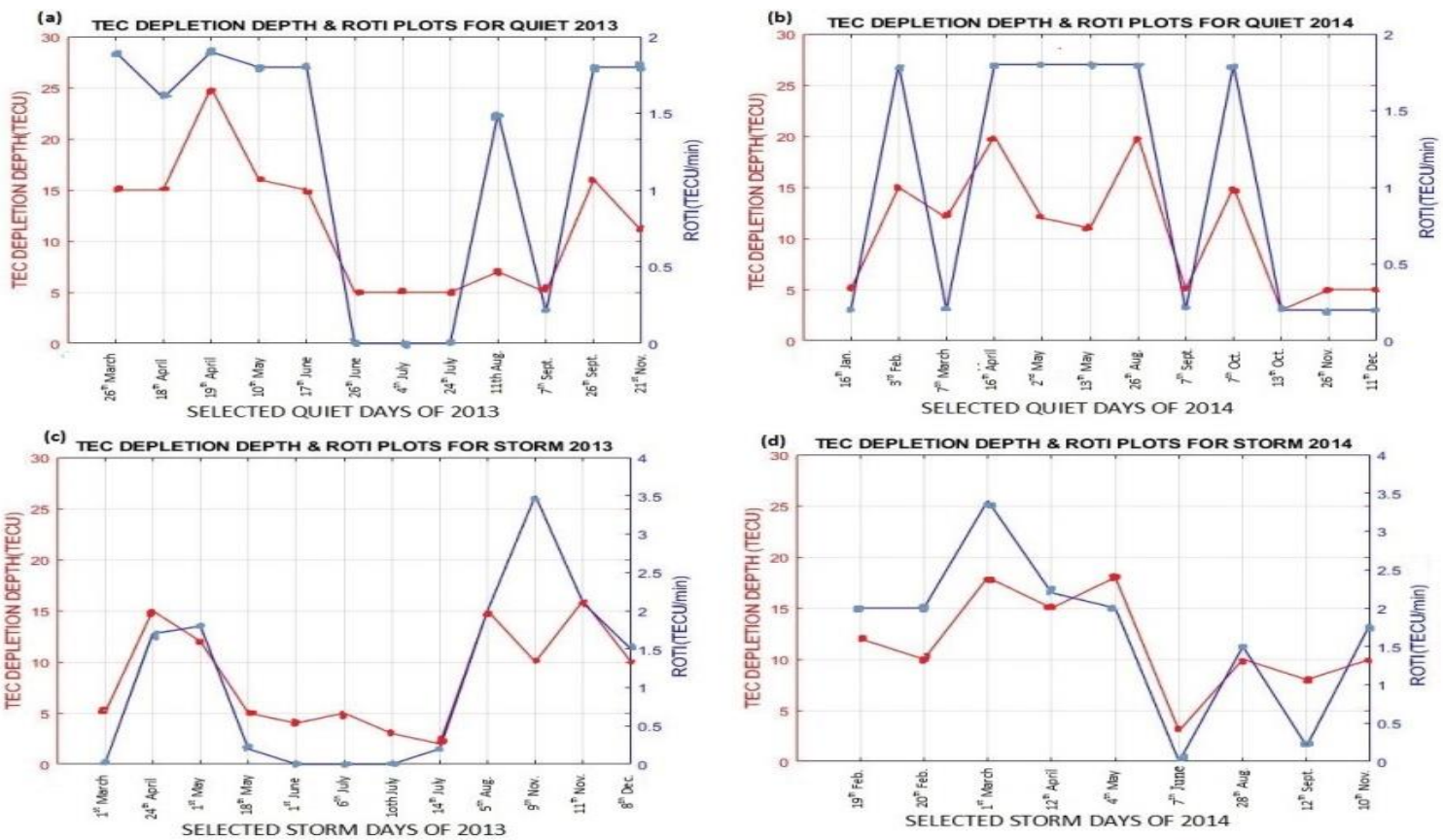

Fig. 2: TEC Depletion Depths and ROTI Plots for Selected Quiet and Storm Days of 2013 and 2014. 
In Fig. 2(c), TEC depletion depth of about 16 TECU was noted with a corresponding ROTI of 2.1 TECU/min on $11^{\text {th }}$ November 2013. $24^{\text {th }}$ April 2013 had a TEC depletion depth of 15 TECU with a corresponding ROTI of 1.8 TECU/min. $5^{\text {th }}$ August 2013 had a TEC depletion depth of 13 TECU with a corresponding enhanced $S_{4}$ index of $3.5 \mathrm{TECU} / \mathrm{min}$ while $1^{\text {st }}$ June $2013,6^{\text {th }}$ July 2013 and $10^{\text {th }}$ July 2013 had TEC depletion depths of 4 TECU, 5 TECU and 3 TECU respectively with a corresponding ROTI of 0 TECU/min.

In Fig. 2(d), TEC depletion of depletion depth of 18 TECU was noted with a corresponding ROTI of 3.4 TECU/min on $1^{\text {st }}$ March 2014. $4^{\text {th }}$ May 2014 had a TEC depletion depth of 18 TECU with a corresponding ROTI of 2 TECU/min. $12^{\text {th }}$ April 2014 had a TEC depletion depth of 15 TECU with a corresponding enhanced ROTI of 2.2 TECU/min while $7^{\text {th }}$ June 2014 had TEC depletion depth of 3 TECU with a corresponding ROTI of 0 TECU/min.

Increased TEC depletions lead to increased fluctuation of ROT and hence higher ROTI values after sunset. In this study, TEC depletion depths had a positive correspondence with ROTI where larger TEC depletion depths were seen to correspond with higher ROTI values after local sunset for most selected quiet and storm days of 2013 and 2014. This is in consistency with studies done by DasGupta et al., (2007) which showed that large TEC depletion depths resulted in larger ROTI values after sunset in both geomagnetically quiet and disturbed conditions. The variation of TEC depletion depths and ROTI for the few selected quiet and storm days resulted from variation in development of the EIA and geomagnetic activity level.

As much as the TEC depletion depths corresponded well with increase in ROTI after local sunset for most days as shown in Fig. 2(a), 2(b), 2(c) and 2(d), there were a few days in which TEC depletion depths and ROTI didn't exhibit a positive correspondence. The days included: $26^{\text {th }}$ March 2013, $17^{\text {th }}$ June 2013 and $21^{\text {st }}$ November 2013 for the selected quiet days of 2013 as indicated in Fig. 2(a); $2^{\text {nd }}$ May 2014, $15^{\text {th }}$ May 2014 and $26^{\text {th }}$ November 2014 for selected quiet days of 2014 as indicated in Fig. 2(b); $2^{\text {nd }}$ May $2013,6^{\text {th }}$ May 2013 and $9^{\text {th }}$ November 2013 for selected strom days of 2014 as indicated in Fig. 2(c) and on $19^{\text {th }}$ February 2014 and $4^{\text {th }}$ May 2014 for the selected storm days of 2014 as indicated in Fig. 2(d). The lack of positive correspondence of TEC depletion depths and ROTI values after sunset for these days was attributed to the presence of short-lived peaks on ROT which were smoothened (detrenched) before calculating and plotting ROTI. A study by Jacobsen, (2014) revealed that when comparing different statistical studies using ROTI, smoothening of the short-lived peaks on ROT is important in obtaining exact ROTI values.

\subsection{Variations of amplitude scintillation $\left(S_{4}\right)$ and ROTI for selected quiet and storm days of 2013 and 2014}

Fig. 3 shows TEC depletion depths and ROTI plots for the selected quiet and storm days of the years 2013 and 2014 between 16:00 and 20:00 UT.

In Fig. 3(a), the highest ROTI values for the selected quiet days of 2013 were 1.9 TECU/min on $26^{\text {th }}$ March 2013 and $19^{\text {th }}$ April 2013 with a corresponding enhanced $\mathrm{S}_{4}$ index of 0.2 and 0.5 respectively. $10^{\text {th }}$ May $2013,17^{\text {th }}$ June $2013,26^{\text {th }}$ September 2013 and $21^{\text {st }}$ November 2013 had a ROTI value of $1.8 \mathrm{TECU} / \mathrm{min}$ with a corresponding enhanced $\mathrm{S}_{4}$ index of $0.35,0.3,0.35$ and 0.2 respectively. The lowest ROTI values $(0 \mathrm{TECU} / \mathrm{min})$ were attained on $26^{\text {th }}$ June $2013,4^{\text {th }}$ July 2013 and $24^{\text {th }}$ July 2013 with corresponding enhanced $\mathrm{S}_{4}$ values of $0.1,0.15$ and 0.3 respectively.

In Fig. 3(b), the highest ROTI values for the selected quiet days of 2014 were 1.8 TECU/min on $3^{\text {rd }}$ March $2014,16^{\text {th }}$ March $2014,2^{\text {nd }}$ May $2014,13^{\text {th }}$ May $2014,26^{\text {th }}$ August 2014 and $7^{\text {th }}$ October 2014 with a corresponding enhanced $\mathrm{S}_{4}$ index of about $0.3,0.5,0.3,0.2,0.3$ and 0.25 respectively. Lowest ROTI values $(0.2 \mathrm{TECU} / \mathrm{min})$ were attained on $16^{\text {th }}$ January $2014,7^{\text {th }}$ March $2014,7^{\text {th }}$ September 2014 , $13^{\text {th }}$ October 2014, $26^{\text {th }}$ November 2014 and $11^{\text {th }}$ December 2014 with enhanced $\mathrm{S}_{4}$ index of about $0.1,0.5,0.3,0.2,0.2$ and 0.2 respectively.

In Fig. 3(c), the highest ROTI value for the selected storm days of 2013 was 3.5 TECU/min on $9^{\text {th }}$ November with a corresponding enhanced $\mathrm{S}_{4}$ of about 0.2 . The lowest ROTI values ( 0 TECU/min) were attained on $1^{\text {st }}$ June $2013,6^{\text {th }}$ July 2013 and $10^{\text {th }} \mathrm{July} 2013$ with a corresponding enhanced $\mathrm{S}_{4}$ index of $0.1,0.1$ and 0.3 respectively.

In Fig. 3(d), the highest ROTI values for the selected storm days of 2014 was 3.4 TECU/min on $1^{\text {st }}$ March 2014 , 4 with a corresponding enhanced $\mathrm{S}_{4}$ of about 0.3 . Lowest ROTI values $(0 \mathrm{TECU} / \mathrm{min})$ was attained on $7^{\text {th }}$ June 2014 with enhanced $\mathrm{S}_{4}$ of about 0.2 .
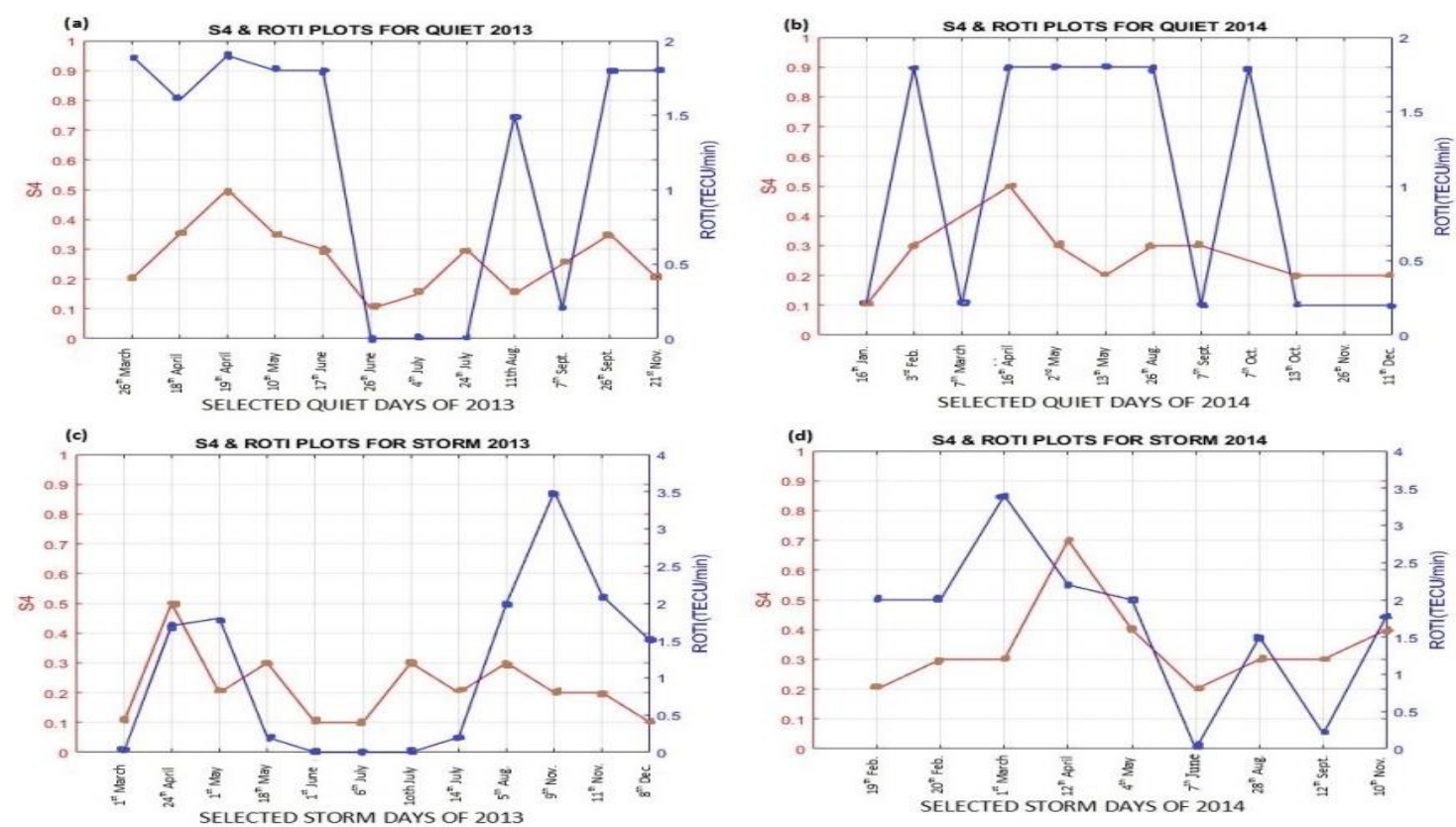

Fig. 3: Amplitude Scintillation $\left(S_{4}\right)$ and ROTI Plots for Selected Quiet and Storm Days of 2013 and 2014. 
A close comparison of ROTI and $\mathrm{S}_{4}$ in Fig. 3(a), 3(b), 3(c) and 3(d), indicates that a rise in ROTI values which to some extend correlate with phase scintillation corresponded well with enhanced $S_{4}$ index after local sunset for most of the selected quiet and storm days of the years 2013 and 2014. However, a few of the selected quiet and storm days of 2013 and 2014 did not show a direct correspondence between ROTI and the enhanced $\mathrm{S}_{4}$ values. This is because as much as amplitude scintillation index is able to show how disturbed the ionosphere is, in most cases the data used to compute ROTI does not cover the scale sizes required to make a complete comparison with $\mathrm{S}_{4}$ index (Beach \& Kintner, 1999). Jacobsen, (2014) observed that ROTI index is seen not to contain information about the irregularity size but it only provides information on the existence of the irregularities within the range limited by the sample rate and the measurement interval. This might be the reason why there was no direct correspondence between $\mathrm{S}_{4}$ and ROTI for some of the selected quiet and storm days of 2013 and 2014 in this study.

\subsection{Inferring occurrence of EPBs using TEC depletion, enhanced $S_{4}$ index, ROT fluctuation and ROTI}

It should be noted from Fig. 1(a), 1(b), 1(c), 1(d), 2(a), 2(b), 2(c), 2(d), 3(a), 3(b), 3(c) and 3(d) that TEC depletion depths corresponded well with enhanced $S_{4}$ index between 16:00 and 20:00UT for most selected quiet and storm days of 2013 and 2014. These TEC depletion depths also corresponded well with higher ROTI values between 16:00 and 20:00 UT for most selected quiet and storm days of 2013 and 2014.

The higher ROTI values between 16:00 UT and 20:00 UT resulted from electron density depletions in the ionosphere which a rise after sunset when the eastward electric field is enhanced, hence increasing the upward plasma drift to higher altitudes. Fejer et al., (1999) observed that the evening vertical drift and pre-reversal enhancement (PRE) plays an important role in the occurrence of post-sunset plasma irregularities since the onset or inhibition of these post-sunset plasma instabilities is majorly controlled by the variability of the PRE.

In this study, the occurrence of EPBs were inferred for any selected quiet or storm day in which the enhancement of $\mathrm{S}_{4}$ corresponded well with TEC depletions of depletion depth $\geq 7$ TECU, increased ROT fluctuations and higher ROTI values $\geq 1.5 \mathrm{TECU} / \mathrm{min}$ between 16:00UT and 20:00UT (after local sunset). Hence for the selected quiet days of 2013, the presence of EPBs were inferred on $26^{\text {th }}$ March 2013, $18^{\text {th }}$ April 2013, 19 $9^{\text {th }}$ April 2013, $10^{\text {th }}$ May 2013, 17 th June 2013, $11^{\text {th }}$ August 2013, $26^{\text {th }}$ September 2013 and $21^{\text {st }}$ November 2013. For selected the quiet days of 2014, the presence of EPBs were inferred on $3^{\text {rd }}$ February 2014, $16^{\text {th }}$ April 2014, $2^{\text {nd }}$ May 2014 , 13 ${ }^{\text {th }}$ May 2014, 26 $6^{\text {th }}$ August 2014 and $7^{\text {th }}$ October 2014. For the selected storm days of 2013, the presence of EPBs were inferred on $24^{\text {th }}$ April 2013, $1^{\text {st }}$ May 2013, $5^{\text {th }}$ August 2013, $9^{\text {th }}$ November $201311^{\text {th }}$ November 2013 and $8^{\text {th }}$ December 2013. Lastly, for the selected storm days of 2014, the presence of EPBs were inferred on $19^{\text {th }}$ April 2014, $20^{\text {th }}$ February 2014, $1^{\text {st }}$ March 2014, 12 $2^{\text {th }}$ April 2014, $4^{\text {th }}$ May 2014 , $28^{\text {th }}$ August 2014 and $10^{\text {th }}$ November 2014. Generally, correspondence of higher ROTI values, increased ROT fluctuation, sharp depletions of TEC and enhanced $\mathrm{S}_{4}$ between 16:00 UT and 20:00 UT conform with earlier researches reported by Nishioka et al., (2008); Zou and Wang, (2009); Zernov et al., (2009) and Adewale et al., (2012) where TEC depletions, increased ROT fluctuations and higher ROTI values were used to characterize the occurrence of plasma bubbles.

\subsection{Yearly EPB occurrence for the years 2013 and 2014}

The EPB occurrence for the selected quiet and storm days of the years 2013 and 2014 were analyzed to obtain the percentage occurrence in both quiet and storm period for each year as shown in Fig. 4. These percentage occurrences for the years 2013 and 2014 were defined as a ratio of the number of days when EPBs were inferred and the total number of selected quiet and storm days under study.

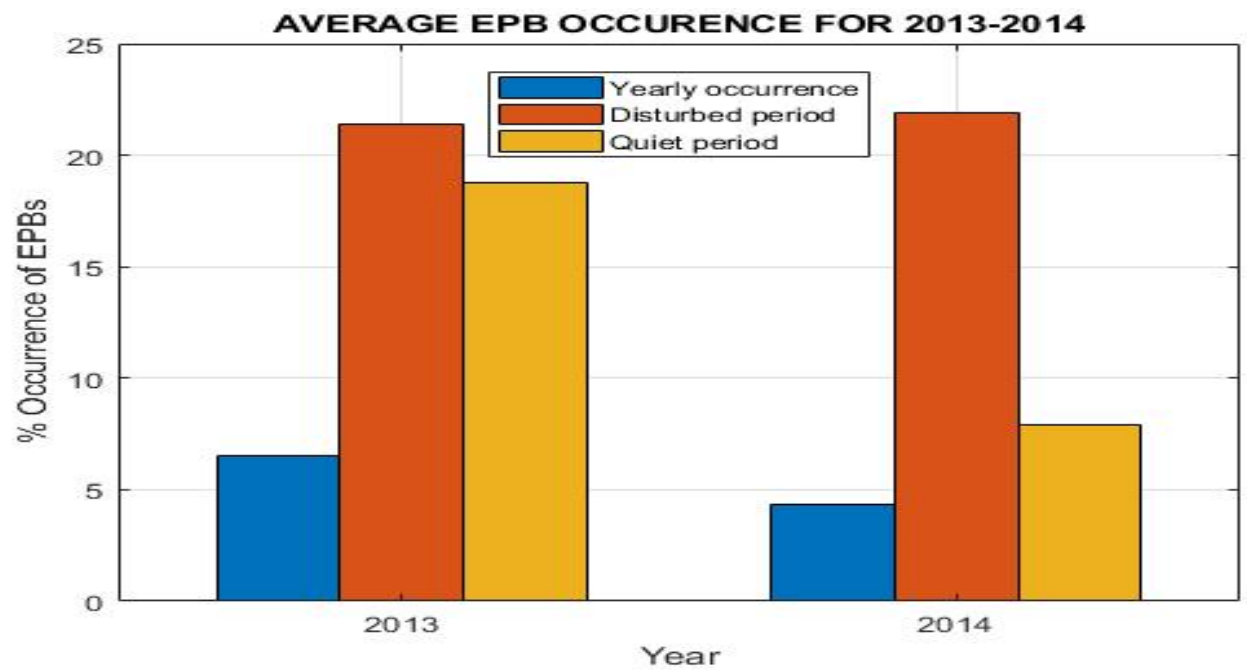

Fig. 4: Percentage EPB Occurrence for the Years 2013 and 2014

Fig. 4 shows a percentage EPB occurrence of $6.49 \%$ in the year 2013 and $4.32 \%$ in the year 2014. The percentage EPB occurrence in the storm period of the year 2013 was $21.42 \%$ while in the storm period of the year 2014 was $21.88 \%$. The percentage EPB occurrence for the quiet period of the year 2013 was $18.75 \%$ while for the quiet period of the year 2014 was $7.89 \%$. It was noted that the percentage of EPB occurrence was higher in the storm period than in the quiet period. These results conform with those from previous studies reported by Abdu et al, (2003); Kil and Paxton, (2006); Li et al., (2006) and Basu et al., (2007) where the occurrence of EPBs were found to be enhanced by geomagnetic activity. Nakata et al., (2018) observed that most EPBs occurred during high geomagnetic activity period since the PPEF which is enhanced during storms favors the occurrence of EPBs during such periods. When geomagnetic storms occur, the ionospheric electric fields at the polar (high latitude) region penetrate towards the low latitude (Nakata et al., 2018). This penetrating electric field called PPEF (Basu et al., 2007; Kikuchi et al., 2008) which is a short duration perturbation (taking a few hours) is eastward in the dusk ionosphere hence enhancing growth of RTI and causes development of plasma bubbles (Abdu et al., 2009; Cherniak et al., 2019) due to increased $\mathbf{E} \mathbf{x}$ B upward drift. In the recovery phase (Huang et al., 2001; Abdu et al, 2009; Bolaji et al., 2019), the direction 
changes in opposite direction due to the development of a shielding current (Kelley et al., 1979; Kikuchi et al., 2008) which increases the opposite polarity of the electric field hence inhibiting the occurrence of EPBs. This electric field is called DDEF (Blanc \& Richmond, 1980; Bhattacharrya et al., 2019). Besides the effects of PPEF and DDEF, the occurrence of EPBs is also affected by storm winds which extend from high latitude regions to low latitude regions. Storm winds lift the ionized regions and modify the atmospheric composition of the equatorial ionosphere, hence affecting the EIA, PRE, VTEC and ROTI. The percentage occurrence of EPBs during storm days is therefore determined by the competing effects of PPEF, DDEF and the storm winds since the DDEF effect is usually delayed and lasts longer than PPEF (Richmond et al., 2003). During the quiet days, the interplanetary magnetic field (IMF) is northward and therefore the enhancement of the eastward electric field brings occurrence of EPBs (Cherniak et al., 2019). It should also be noted that the occurrence of EPBs over Kisumu, Kenya during this period might have been strongly influenced by neutral winds dynamo which is driven by the Eregion neutral winds which are usually generated by convection and flow from West to East in the evening in Kenya (Mukabana \& Pielke, 1996) and leads to production of electric field enhancement (Omondi et al., 2014). Neutral winds are driven by pressure gradient of the neutral atmosphere as a result of solar heating (Otsuka, et al., 2006).

\subsection{Seasonal occurrences of EPBs for the years 2013 and 2014}

The seasonal occurrences of equatorial plasma bubbles for the years 2013 and 2014 were analyzed by classifying them into four seasons for each year where the March equinox comprised of months of March and April; June solstice comprised of months of June and July; September equinox comprised of months of August and September while the November solstice compromised of months of November and December. The results were represented as shown in Fig. 5.

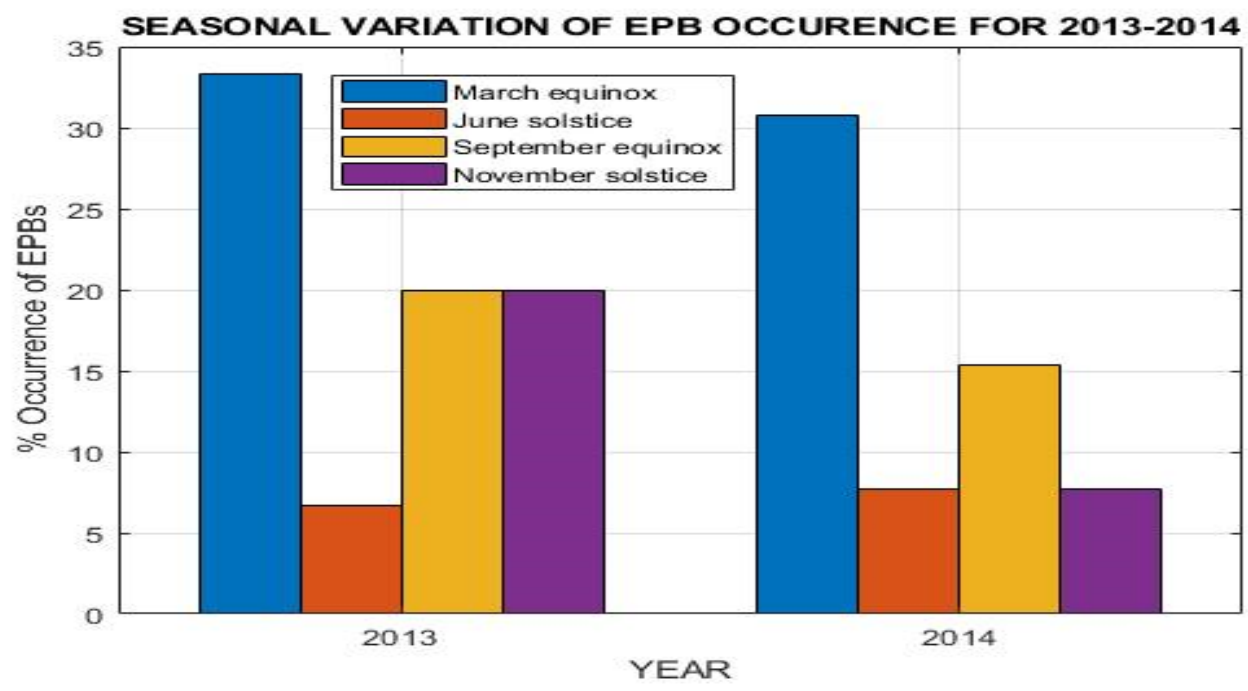

Fig. 5: Seasonal Variation of EPBs for the years 2013 and 2014.

In Fig. 5, the percentage EPB occurrence for March equinox was 33.33\% in the year 2013 and 30.76\% in the year 2014. The percentage EPB occurrence for September equinox was $20.38 \%$ in the year 2013 and $17.26 \%$ in the year 2014. The percentage EPB occurrence for June solstice was $6.67 \%$ in the year 2013 and $7.69 \%$ in the year 2014. The percentage EPB occurrence for November solstice was $30.76 \%$ in the year 2013 and $7.69 \%$ in the year 2014. It was noted that the percentage of EPB occurrence was higher during the equinoctial period (March, April, August and September) than the solstice period (June, July, November and December) in the years 2013 and 2014. This is because during equinoctial period, the solar terminator is aligned with the local geomagnetic field lines and hence there is increased photoionization resulting from high SEUV radiation during the period, leading to formation of irregularities. Studies by Sahai et al., (2000) and Huang et al., (2002) have shown that the percentage of EPB occurrence increases during periods of high solar activity. The results obtained in this study conform with those obtained by Paznukhov et al., (2012) and Magdaleno et al., (2017) where highest occurrence of EPBs were observed during equinoctial months. The seasonal variation of EPB occurrence where equinoctial period had higher percentage EPB occurrence while solstice period had lower percentage EPB occurrence was attributed to the effect of the PRE of the eastward electric field which induces increase in vertical $\mathbf{E} \times$ B drift (Abdu et al., 1981; Batista et al., 1996; Murkherjee et al., 2010). The equinoctial period (March, April, August and September) and the November solstice period (November and December) have larger daytime $\mathbf{E} \times \mathbf{B}$ drift velocities than the June solstice period (June and July). June solstice had the lowest percentage EPB occurrence and this was due to the lower $\mathbf{E} \times \mathbf{B}$ vertical drift during the June solstice resulting from reduced eastward electric field. These results conform with those obtained by Cherniak et al., (2019) where the lowest percentage of EPB occurrence was in June solstice. Fejer et al., (2008) showed that the vertical drift associated with PPEF is upward during daytime and downwards during nighttime in all seasons and they reach peak seasons during the June solstice. Consequently, the DDEF has a downward drift during daytime and an upward drift during nighttime and has been shown to increase with solar flux and are therefore largest during equinox and smallest in June solstice.

\section{Conclusions}

We have investigated the occurrence of EPBs over Kisumu, Kenya for a few selected quiet and storm days of 2013 and 2014 using TEC data obtained from SCINDA-GPS. The obtained results showed that TEC depletions and enhanced $\mathrm{S}_{4}$ index corresponded well with increased ROT fluctuations and higher ROTI values between 16:00UT and 20:00UT for most selected quiet and storm days and was used as a proxy for inferring EPB occurrence. The storm period exhibited a higher percentage of EPB occurrences than the quiet period for the 2013 and 2014 study period. The higher EPB occurrence during storm period was attributed to PPEF which favors development of EPBs during storm period by enhancing the eastward electric field which enhances the vertical $\mathbf{E} \times \mathbf{B}$ drift. 
On the seasonal variation of EPBs, the results showed that the equinoctial period (March, April, August and September) had a higher percentage of EPB occurrence than the solstice period (June, July, November and December) for the years 2013 and 2014 , which is in agreement with most ground-based observations. Furthermore, the asymmetry of EPB occurrence between equinoxes and between solstices was also observed where the March equinox had a higher percentage EPB occurrence than the September equinox for both years while November solstice had a higher percentage EPB occurrence than the June solstice for the year 2013 . However, the year 2014 showed a similar solstice symmetry by having the same percentage EPB occurrence for June solstice and November solstice. Generally, the year to year percentage EPB occurrence showed a higher EPB occurrence in the year 2013 than in the year 2014.

In conclusion, this study confirms the occurrence of EPBs over Kisumu, Kenya during both geomagnetically quiet and geomagnetically disturbed days for the years 2013 and 2014.

\section{Acknowledgements}

The authors are grateful to Boston College and the Air Force Research Laboratory (AFRL), USA who supplied the Kisumu SCINDAGPS receiver at Maseno University that was used to access research data and Masinde Muliro University of Science and Technology (MMUST) for provision of library and internet facilities while undertaking the research. They also thank the anonymous reviewers for evaluating the paper.

\section{References}

[1] Abdu, M., Bittencourt, J. and Batista, I. (1981). Magnetic declination control of the Equatorial F-region dynamo electric field development and spread F, J.Geophys. Res.-Space, 86, 11443-11446, 1981. https://doi.org/10.1029/JA086iA13p11443.

[2] Abdu, M. A., Batista, I. S., Takahashi, H, MacDougall, J., Sobral, J. H., Medeiros, A. F. and Trivedi B. (2003). Magnetospheric disturbance induced equatorial plasma bubble development and dynamics. A case study in Brazilian sector. Journal of Geophysical Research, 108 (A12), 1449. https://doi.org/10.1029/2002JA009721.

[3] Abdu, M. A., Kherani, E. A., Batista, I. S. and Sobrai, J. H. A. (2009). Equatorial evening pre-reversal vertical and spread-F suppression by disturbance penetration electric field. Geophys Res Lett 36:119103. https://doi.org/10.1029/2009GL039919.

[4] Adetayo, V. E., Adewale, A. O., Akala, A. O., Bolaji, O. S. and Rabiu A. B. (2017). Studying the variability in the diurnal variations of GPS TEC over Nigeria.Ann. Geophys, 35,701-710, https://doi.org/10.5194/angeo-35-701-2017.

[5] Adewale A. O., Oyeyemi E. O., Adeloye A. B. , Mitchell C. N. , Rose J. A. R. and Cilliers P. (2012). A study of L-band scintillations and total electron content at an Equatorial Station. Lagos, Nigeria. Radio science, vol. 47, RS2011, https://doi.org/10.1029/2011RS004846.

[6] Basu, S., Basu, S., Rich, F. J., Grooves, K. M., Mackenzie, E., Coller, C., Sahai, Y., Fagundes, P. R. and Becker-Guedes, F. (2007). Response to the equatorial ionosphere at dusk to penetration electric fields during intense magnetic storms. J Geophys. Res, 112:A08308. https://doi.org/10.1029/2006JA012192.

[7] Barros, D.,Takahashi, H.,Wrasse, C. M. and Figueiredo C. A. O. B. (2018). Characteristics of Equatorial Plasma Bubbles observed by TEC map based on ground-based GNSS Receivers over South America. Ann. Geophys., 36,91-100,2018. https://doi.org/10.5194/angeo-36-91-2018.

[8] Battacharyya, A., Beach, T. L., Basu, S. and Kintner, P. M. (2000). Night-time equatorial ionosphere: GPS scintillations and differential carrier phase fluctuations, Radio Sci., 209-234. https://doi.org/10.1029/1999RS002213.

[9] Bhattacharyya, A., Fedrizzi, M., \& Fuller-Rowell, T. J., Gurram, P.,Kakad, B., Sripathi, S. and Sunda, S. (2019). Effect of magnetic related storm thermospheric changes on evolution of equatorial plasma bubbles. Journal of Geophysical Research, space physics, 124, $2256-2270$. https://doi.org/10.1029/2018JA025995.

[10] Batista, I., Medeiros, R. D., Abdu, M., Souza, J. D., Bailey, G. and Paula, E. D. (1996). Equatorial ionosphere vertical plasma drift model over Brazilian region, J. Geophys. Res.-Space, 101, 10887-10892, 1996. https://doi.org/10.1029/95JA03833.

[11] Beach, T. L., and P. M. Kintner (1999). Simultaneous Global positioning system observations of equatorial scintillations and total electron fluctuations. J. Geophys. 22, 553-22, 565, 1999. https://doi.org/10.1029/1999JA900220.

[12] Blanc, M. and Richmond, A. D. (1980).The ionospheric disturbance dynamo. J Geophys. Res, 85:1669-1686. https://doi.org/10.1029/JA085iA04p01669.

[13] Bolaji, O. S., Adebiyi, S. J. and Fashae J.B. (2019). Characterization of ionospheric irregularities at different longitudes during quiet and disturbed geomagnetic conditions. Journal of Atmospheric and Solar-terrestrial physics. https://doi.org/10.1029/2004JA010583.

[14] Caruana, P., Du, J., Wilkinson, P., Thomas, R. and Cervera, M. (2018). Determination of equatorial ionospheric scintillations $\mathrm{S}_{4}$ dual frequency GPS: Proceedings WAR'00: Workshop on applications of Radio Science, 27-29 April 2000, La Trobe University, pg. 85-90, http://www.ips.gov.au/IPS Hosted/NCRS/wars/wars2000.index.htm

[15] Cherniak, I., Zakharenkova, I. and Sokolvsky, S. (2019). Multi-instrumental observation of storm induced ionospheric plasma bubbles at equatorial and middle latitudes. Journal of research. Space physics.124, 1497-1508. https://doi.org/10.1029/2018JA026309.

[16] DasGupta, A., Paul, A. and Das, A.(2007). Ionospheric Total Electron Content (TEC) studies with GPS in the Equatorial region. PACs No.94.20.YX;94.20.VV.94.20.WW, 2007

[17] Eastwood, J. P., Biffis, E., Hapgood, M. A., Green, L., Bisi, M. M., Bentley, R. D., Wicks, R.,Mckinell, L. A., Gobbs, M. and Burnett, C. (2017). The economic impact of space weather:Where do we stand?Risk analysis.Vol. 37, No.2, 2017Doi:10.1111/risa.12765

[18] Fayose, R.S., Oladosu, O.R., Rabiu, A.B. and Grooves, K. (2012).Variation of Total Electron Content [TEC] and their Effect on GNSS over Akure,Nigeria. doi:10.5539/apr.v4n2p105. https://doi.org/10.5539/apr.v4n2p105.

[19] Fejer, B. G., Scherliess, L., de Paula, E. R. (1999). Effects of the vertical plasma drift velocity on the generation and evolution of equatorial spread F. Journal of Geophy. Res, vol 104, No. A9, 859-19, 869. https://doi.org/10.1029/1999JA900271.

[20] Fejer, B. G., Jensen, J. W. and Su, S. Y. (2008). Seasonal and longitudinal dependence of equatorial disturbance vertical plasma drifts, Geophys. Res. Lett., vol. 35, L20106. https://doi.org/10.1029/2008GL035584.

[21] Huang, C.,Burke, W., Machuzak, J., Gentile, L. and Sultan, P. (2002). Equatorial plasma bubbles observed by DMSP satellites during a full solar cycle: Towards a global climatology, J.Geophys. Res. space, 107, https://doi.org/10.1029/2002JA009452.

[22] Huang, C. Y., Burke, W. J., Ma Chuzak, J. S. and Gentile, L. C. and Sultan, P. J. (2001). DMSP Observations of equatorial plasma bubbles in the topside ionosphere near solar maximum. Journal of Geophysical Research, vol.106, No.A5, pg 8131-8142. https://doi.org/10.1029/2000JA000319.

[23] Kelley, M. C., Fejer, B. G. and Gonzales, C. A. (1979). An explanation from anomalous equatorial ionospheric fields associated with a northward turning of the interplanetary magneticfield.Geophys.ResLett6:301-304. https://doi.org/10.1029/GL006i004p00301.

[24] Kelley, M. C., Rodrigues, G. S., Makela, J. J., Tsunoda, R., Roddy, P. A., Retterer, J. M., de La Beaujardiere, O., de Paula, E. R. and Ilma, R. R. (2009). C/NOFS and radar observations during consecutive ionospheric storm event over South America. Geophys. Res.Lett., 36, L00c07, https://doi.org/10.1029/2009GL039378.

[25] Kikuchi, T., Hashimoto, K. K. and Nozaki, K. (2008). Penetration of magnetospheric electric fields to the equator during a geomagnetic storm. J Geophys. Res 113.a06214. https://doi.org/10.1029/2007JA012628.

[26] Kil, H. and Paxton, L. J. (2006). Ionospheric disturbances during the magnetic storm of 15th July 2000: Role of the fountain effect and plasma bubbles for the formation of large equatorial plasma density depletions. JGeophys.Res.111.A1231, https://doi.org/10.1029/2006JA011742. 
[27] Jacobsen, K. S. (2014). The impact of different sampling rates and calculation time intervals on ROTI values. Jspace weather space Clim., 4, A33(2014). https://doi.org/10.1051/swsc/2014031.

[28] Li, G., Ning, B., Wan, W. and Zhao, B.(2006). Observations of GPS ionospheric scintillations over Wuhan during geomagnetic storms. Ann Geophys 24:1581-1590. https://doi.org/10.5194/angeo-24-1581-2006.

[29] Magdaleno, S., Herraiz M., Altadill, D. and De la Morena. (2017). Climatology characterization of equatorial plasma bubbles using GPS data. .J.Space Weather Space Clim,7 A3 (2017). https://doi.org/10.1051/swsc/2016039.

[30] Milos, M. (2014). Determination of TEC in the ionosphere using GPS Technology. Vol. 2, No. 2, https://doi.org/10.5194/angeo-22-3109-2004.

[31] Makela, J. J., Ledvina, B. M., Kelley, M. C. and Kintner, P. M. (2004). Analysis of seasonal variation of Equatorial plasma bubbles occurrence observed from Haleakala, Hawaii. Annales Geophysica (2004) 22:3109-3121.SRef-ID: 1432-0576/ag/2004-3109.

[32] Mukabana, J. R. and Pielke, R. A. (1996). Investigating the influence of synoptic-scale monsoonal winds and mesoscale circulations on Diurnal weather patterns Over Kenya using numerical model, American Meteorological Society, Monthly Weather Review, Vol 124.

[33] Mukherjee, S., Sarkar, S., Purohit, P. K., and Gwal, A. K. (2010). Seasonal variation of Total Electron Content at crest of equatorial anomaly station during low solar activity conditions, Adv. Spac Res., 46, 291-295, 2010. https://doi.org/10.1016/j.asr.2010.03.024.

[34] Nakata, H., Takahashi A., Takano T., Jaito A. and Sakanoi T. (2018). Observation of equatorial plasma bubbles by airglow imager on ISS-IMAP. Earth and planetary science. https://doi.org/10.1186/s40645-018-0227-0.

[35] Ndeda, O. H., and Odera, P. O. (2014). Analysis of Longitudinal Advancement of the peak Total Electron Content in the African equatorial anomaly region using data from GPS receivers and GIS stations in Kenya, Canadian Centre of Sc. \& Educ. Applied Phys. Research: vol. 6, No. 1; 2014. https://doi.org/10.5539/apr.v6n1p19.

[36] Nishioka, M., Saito, A., Takano T. and Tsugawa T. (2008). Occurrence characteristics of plasma derived from global-ground based GPS receiver networks. J.Geophys, Res., 113,A05301, https://doi.org/10.1029/2007JA012605.

[37] Olwendo, J. O., Cilliers, P. J., Baki, P. and Mito, C. (2012). Using GPS-SCINDA observations to study the correlation between scintillation, total electron content enhancement and depletions over the Kenyan region: Advances in Space Research 49 (2012) 1363-1372. https://doi.org/10.1016/j.asr.2012.02.006.

[38] Omondi, G., Ndinya, B. and Baki, P. (2014). Study of the Equatorial ionosphere over Nairobi during selected magnetically disturbed and quiet times for the year 2009 using co-located instruments. IJARPS, Vol 1, 18-26, 2014.

[39] Omondi, G. E., Baki, P., Ndinya, B. O. (2019). Total electron content and scintillations over Maseno, Kenya during high solar activity year. Acta Geophysica. https://doi.org/10.1007/s11600-019-00354-7.

[40] Otsuka, Y., Shiokawa, K. and Ogawa, T. (2006). Equatorial Ionospheric scintillations and Zonal irregularity Drifts observed with closely Spaced GPS receivers in Indonesia. Journal of the Meteorological Society of Japan, Vol 84A, pp 343-351, 2006.

[41] Paznukhov, V. V., Carrano C. S., Doherty P. H., Grooves K. M., Caton R. G., Valladares C.E., Seemala G.K., Bridgwood C.T., Adenyi J., Ameshi L.L.N., Damtie B., Dujanga F.D., Ndeda J.O.H., Baki P.,Obrou O.K., Okere B. and Tsidu G. M. (2012). Equatorial plasma bubbles and L-band scintillations in Africa during solar minimum: Annales Geophysica, 30, 675-682, 2012. https://doi.org/10.5194/angeo-30-675-2012.

[42] Pi, X, Mannucci, A. J., Lindquister, U. J. and HO, C. M. (1997). Monitoring of Global Ionospheric irregularities using the worldwide GPS network. Geophys. Res. Lett, 24 (18), 2283-2286, 1997. https://doi.org/10.1029/97GL02273.

[43] Radicella, S. (2012). Workshop on science applications of GNSS in developing countries (11-27 April) followed by the Seminar on Development and use of ionospheric Ne Quick model 30th April -1st May 2012.

[44] Richmond, A. D., Peymirat, C. and Roble, R. G. (2003). Long-lasting disturbances in the equatorial ionospheric electric field simulated with a coupled magnetosphere-ionosphere thermosphere model. JGeophysRes108.1118. https://doi.org/10.1029/2002JA009758.

[45] Sahai, Y., Fagundes, P. and Bittencourt, J. (2000). Trans-equatorial F-region ionospheric plasma bubbles: Solar cycle effects, J. Atmos. Sol. Terr. Phys., 62, 1377-1383, 2000. https://doi.org/10.1016/S1364-6826(00)00179-6.

[46] Wang, C., Shi, C., Fan, L. and Zhang, H. (2018). Improved modeling of Global Ionospheric Total Electron content using prior information. Remote sens2018, 10, 63 https://doi.org/10.3390/rs10010063.

[47] Zernov, N. N., Gherm, V. E. and Strangeways H. J. (2009). On the effects of scintillation of low-latitude bubbles on trans-ionospheric paths of propagation, Radio Sci., 44, https://doi.org/10.1029/2008RS004074.

[48] Zou, Y. and Wang, D. (2009). A study of GPS ionospheric scintillations observed at Guilin, J. Amis. Sol. Terr.Phys., 71, 1948-1958, https://doi.org/10.1016/j.jastp.2009.08.005. 